\title{
O Investimento Social na União Europela como Resposta aos Desafios Financeiros e Sociais da Crise*
}

\section{Laura Gómez Urquijo**}

\section{Introdução}

O investimento social se introduz desde a metade dos anos 1990 por parte de diferentes governos, que adaptam suas políticas procurando outra via ao Estado de bem-estar além do neoliberalismo. Embora com muita heterogeneidade, há movimentos para o investimento social com a perspectiva de incrementar a inclusão social, minimizar a transferência da pobreza entre gerações, assim como assegurar que a população esteja bem preparada para as condições de emprego previsíveis; este enfoque implica em maior atenção às famílias, às crianças e ao capital humano, e dirige o custo para o trabalho (NIKOLAS, 2009; JENSON, 2011). Estudos recentes analisam a diversa adaptação dos Estados de bem-estar europeus a uma estratégia

\footnotetext{
* Artigo recebido em 21 de novembro de 2013 e aprovado para publicação em 24 de setembro de 2014. Artigo traduzido por Gabriela Barbosa. E-mail: gabriela67@yahoo.com.

** Professora associada da Universidade de Deusto, Bilbao, Espanha. E-mail: laura.gomez@ deusto.es.
} 
Laura Gómez Urquijo

de investimento social (VANDENBROUCKE et al., 2013) e concluem que aqueles que introduzem mais medidas neste sentido têm tido um melhor desempenho socioeconômico e enfrentam melhor a crise (HEMERIJCK et al., 2013). Esta adaptação dos objetivos sociais da União Europeia (UE) pode ser também observada à luz da doutrina sobre resiliência no neoliberalismo (REID, 2012; ZEBROWSKI, 2009); em especial, sobre a resiliência como marco que informa a governança (CHANDLER, 2014).

Entre os aspectos essenciais do atual conceito de investimento social, encontra-se a geração de dividendos em médio e longo prazo, assim como a ideia que o Estado de bem-estar descansa sobre o número e produtividade dos futuros contribuintes. Assim, a política social deveria contribuir ativamente para a mobilização do potencial produtivo dos cidadãos para mitigar futuros riscos sociais. O investimento social não substitui a proteção social, mas a requer como condição prévia. As despesas em proteção social se entendem como poderosos estabilizadores da atividade econômica em nível macroeconômico, já que mantêm a demanda em tempos de recessão; os orçamentos contracíclicos dos governos são importante ganho nesse sentido, como se tem demonstrado nos primeiros anos da crise (VANDENBROUCKE et al., 2011, p. 6-8).

Não é objetivo deste trabalho aprofundar-se no desenvolvimento teórico do conceito de investimento social, já amplamente estudado (VAN KERSBERGEN; HEMERIJCK, 2012; CANTILLON, 2011), mas olhar como dele, e das críticas realizadas à falta de investimento social em alguns Estados-membros, desprende-se a recente abordagem da UE sobre esta questão. Para isso, baseia-se no estudo das iniciativas e propostas da UE, no momento de especial relevância perante as demandas da crise, sob a clara liderança da Comissão.

Assim, neste trabalho se focaliza, em primeiro lugar, o modo como esta instituição coloca a fixação de objetivos sociais e seu seguimen- 
O Investimento Social na União Europeia como Resposta aos Desafios Financeiros...

to durante a crise, chamando a atenção para a dupla intervenção (Estados-UE) na política social. A seguir, fixa-se na contribuição realizada pelo Pacote de Investimento Social, lançado em 2013. Considerando as iniciativas anteriores, a Comissão afirma que "a iniciativa oferece um guia para ajudar a atingir as metas de Europa 2020, estabelecendo um vínculo entre as políticas sociais, as reformas recomendadas no Semestre Europeu para atingir as metas e os correspondentes fundos da UE" (COMISIÓN EUROPEA, 2013a, p. 4). Esta afirmação permite o questionamento sobre, por último, em que medida se produz efetivamente esse vínculo entre as recomendações da Comissão a favor do investimento social e as políticas dos Estados-membros dentro das particulares regras do jogo da atual governança econômica.

\section{A Coordenação dos Estados-membros por Parte da UE para o Cumprimento dos Objetivos Sociais 2020}

A atual abordagem da UE para o investimento social se enquadra no mandato do artigo 3 do Tratado de Funcionamento da União Europeia para o estabelecimento de uma economia social de mercado que aspire ao pleno emprego e ao progresso social com alto nível de proteção. Deve considerar que a institucionalização do sistema de economia social de mercado dá às autoridades europeias ampla margem para configurar e aplicar modelos diversos, acordes com as diferentes políticas nacionais, com variações na qualidade ou grau de proteção social (UN SISTEMA..., 2012, p. 9). Em definitivo, o estabelecimento de objetivos sociais implica na dupla intervenção por parte da UE e dos Estados-membros.

Essa dupla implicação tem se plasmado no Método Aberto de Coordenação, baseado no princípio de subsidiariedade, em objetivos acordados em comum, procedimentos de vigilância e na integração 
das políticas econômicas, de emprego e social (HEIDENREICH; BISCHOFF, 2008, p. 525). É verdade que a política social na UE tende a ser mais intergovernamental que em outras áreas como o mercado interior; mas, de qualquer forma, trata-se de uma experiência de governança que tem sido valorada positivamente para atingir objetivos sociais e a sua renovação em vários países com assimetrias importantes e diferentes modelos de Estado de bem-estar.

Portanto, a coordenação de objetivos sociais não pode ser entendida como homogeneização dos modelos de Estado de bem-estar que se dão atualmente na EU e cujas diferenças persistem. Uma clara manifestação destas diferenças é o caso que se produz com a crise de dívida pela qual atravessa a zona do euro e os esforços por controlar o déficit. Dessa forma, e no momento atual, é importante sublinhar a diversidade que oferecem os diferentes Estados-membros no modo de afrontar seus ajustes para cumprir com a disciplina fiscal (FERREIRO et al., 2012). Nesta situação, indaga-se qual o significado e a virtualidade da coordenação de políticas levadas a cabo pela Comissão e seu impacto real nos Estados-membros, assumida a sua diversidade. A Comissão Europeia entende essa coordenação de políticas sociais como um aspecto essencial para responder pela falta de confiança ocasionada nos mercados durante a crise (EUROPEAN COMMISSION, 2010).

Certamente, desde a crise têm sido numerosas as iniciativas da UE para coordenar objetivos sociais, começando pela Estratégia 2020 (COMISIÓN EUROPEA, 2010a). Destaca-se como nela não somente se determinam metas relativas ao emprego, pobreza ou meio ambiente, mas também se quantificam, fixando um prazo para consecução. Para seu cumprimento, desdobram-se, entre outras iniciativas emblemáticas da Estratégia, a Plataforma Europeia contra a Pobreza e a Exclusão Social (COMISIÓN EUROPEA, 2010b). Por sua vez, a Proposta de Regulamento para a Mudança e a Inovação Social (COMISIÓN EUROPEA, 2011a) propõe também como atingir os 
O Investimento Social na União Europeia como Resposta aos Desafios Financeiros...

objetivos 2020 considerando a experimentação social como um instrumento que pode guiar a reforma e a adaptação das políticas necessárias para tornar realidade a visão da Estratégia. Entre seus objetivos-chave, encontram-se a criação de empregos e a luta contra a exclusão social.

A inclusão social e a luta contra a pobreza como aspectos ligados à promoção do crescimento são reforçadas na medida em que a crise avança. Esse enfoque aborda especialmente a "Acción para el crecimiento, la estabilidad y el empleo" (COMISIÓN EUROPEA, 2012e): a participação das mulheres no mercado trabalhista, o desemprego juvenil, a redução da evasão escolar e o aumento da empregabilidade através da flexibilização da legislação trabalhista estão entre as suas prioridades. Outras iniciativas que antecedem à Comunicação sobre o Investimento Social, e que são citadas por ela, são o Pacote sobre uma Recuperação Geradora de Emprego (COMISIÓN EUROPEA, 2012b) assim como a iniciativa dedicada ao emprego juvenil (COMISIÓN EUROPEA, 2012c) e aquela relativa ao Livro Branco, para garantir que as aposentadorias sejam adequadas, seguras e sustentáveis (COMISIÓN EUROPEA, 2012d).

Apesar dessas iniciativas, os objetivos sociais colocados na Estratégia 2020 são prontamente descumpridos (EUROPEAN COMMISSION, 2012a; EUROSTAT, 2012; 2013). Inclusive, perante o reconhecimento dos primeiros sinais de recuperação econômica, persistem, por um lado, a debilidade dos mercados de trabalho com a precariedade dos contratos, o incremento do desemprego de longa duração e uma elevadíssima taxa de desemprego juvenil (23\%). Por outro lado, uma quarta parte da população da UE está em risco de pobreza ou exclusão, estando a maior porcentagem da população nesta situação, daqueles em idade laboral. Aumenta também o número de trabalhadores em situação de pobreza pela referida precariedade do mercado, ao trabalhar menos horas e com salários mais baixos. Esta situação se manifesta também no incremento do número de crianças 
expostas ao risco de exclusão. Por outro lado, constata-se a extensão da divergência, tanto entre os Estados-membros quanto dentro de cada um deles em relação a diferentes grupos de população. A discordância entre países tem-se manifestado especialmente desde 2010, notando-se mais entre os integrantes da União Econômica e Monetária. Assim, os impactos que mais chamam a atenção sobre a piora dos mercados trabalhistas e o aumento da pobreza foram detectados nos países do Sul, como Grécia ou Espanha. Dentro dos Estados, acentua-se notavelmente a polarização entre lares ricos e pobres, o que indica subutilização do capital humano e diminuição do investimento em capital humano futuro (EUROPEAN COMMISSION, 2014a).

A situação descrita e, em particular, a divergência entre Estados nos levam, por um lado, a destacar o caráter demasiado amplo das mencionadas formulações iniciais da Comissão para a coordenação de objetivos sociais. A falta de uma supervisão efetiva e a pressão que sofrem os Estados da zona do euro para o recorte dos seus déficits deixam uma ampla margem de ação aos governos nacionais para impactar no cumprimento dos objetivos 2020. Situamo-nos com os estudos de Avram et al. (2013), que enfatiza a incidência das políticas de consolidação fiscal na posição dos segmentos mais pobres da população. A valoração da própria Comissão vinha também constatando, no contexto da crise, o desenho das medidas de consolidação fiscal implantadas por cada Estado, um claro impacto na capacidade dos sistemas sociais para oferecer políticas efetivas e adequadas (EUROPEAN COMMISSION, 2013c, p. 67-69).

Entende-se que a ideia de investimento social surgida na UE e que se desenvolve a seguir deve ser situada neste contexto de crise e lançamento de objetivos comuns por parte da Comissão, mas com uma ampla margem de ação dos Estados-membros em matéria social e que, portanto, mantém importantes divergências entre si. 
O Investimento Social na União Europeia como Resposta aos Desafios Financeiros...

\section{Aportes da "Comunicação em Direção ao Investimento Social para o Crescimento e a Coesão na Modernização das Políticas Sociais"}

O "Pacote de Investimento Social" contém a "Comunicação em direção ao investimento social para o crescimento e a coesão, incluída a execução do Fundo Social Europeu" (COMISIÓN EUROPEA, 2013c) e vários documentos de trabalho referidos a questões que tratam das tendências e desafios sociais da UE (como a inclusão no mercado trabalhista, a falta de lar, a pobreza, a situação da infância ou da terceira idade). ${ }^{1}$ A crise atual é o ponto de partida desta Comunicação, porque tem demonstrado a importância dos sistemas de bem-estar para dar estabilidade à UE e também a incapacidade da política social atual para responder aos desafios surgidos. Não se pode esquecer que as políticas sociais são competência dos Estados-membros, neste momento mais ou menos pressionados para que atinjam os objetivos do déficit. Isto implica em importantes divergências entre si, o que leva a Comissão a requerer uma maior coordenação desde a UE e um maior apoio dos seus fundos. É por isso que se coloca como objetivo a sustentabilidade financeira nos sistemas de proteção social, fazendo o melhor uso possível dos fundos da UE e, em particular, do Fundo Social Europeu. Acompanhando esta abordagem, o Conselho celebrado em 22 de fevereiro de 2013 propôs a redução do gasto público através de reformas estruturais simultâneas ao fomento de políticas de integração ativa e mitigando as consequências sociais da crise para as pessoas em situações mais vulneráveis. A melhoria da eficácia dos sistemas de proteção social, em qualidade de estabilizadores automáticos, em combinação com uma maior proteção do mercado de trabalho é considerada como chave para perseguir os objetivos de redução da pobreza e de integração social em um contexto de recursos financeiros limitados (CONSEJO EUROPEO, 2012). 
Deste modo, o conceito de investimento social tratado pela UE se concretiza em responder à peculiar situação do momento: responder aos desafios demográficos e sociais - adaptando as políticas sociais para aperfeiçoar sua eficácia - e responder aos desafios financeiros aperfeiçoando o seu financiamento. Com a sua abordagem, a Comissão aspira a reorientar as políticas dos Estados-membros em direção ao investimento social com o objetivo de garantir a adequação dos sistemas sociais à nova situação social e financeira. A seguir se destacam as ideias mais inovadoras desta abordagem frente às formulações anteriores da UE.

\subsection{Resposta aos desafios demográficos e sociais}

Este pacote parte do reconhecimento de que, tal como se assinalou, a crise acentuou o questionamento da eficácia das políticas sociais; reconhecendo seu impacto positivo nos inícios da crise, no momento atual se mostram incapazes de cobrir as necessidades suscitadas pelo incremento do desemprego e da pobreza. Na Comunicação sobre o Investimento Social (COMISIÓN EUROPEA, 2013a), a Comissão assume explicitamente as citadas críticas sobre a falta de investimento social em alguns dos Estados-membros, tratando de estimular este enfoque para reduzir os desequilíbrios detectados na UE, dando um passo além a respeito das iniciativas anteriormente mencionadas.

Seguindo o avanço na Comunicação, uma indústria europeia mais forte para o crescimento e a recuperação econômica (COMISIÓN EUROPEA, 2012e), o investimento em capital humano é entendido como a base da produtividade e da inovação que leva à competitividade e ao crescimento econômico futuro. O enfoque de investimento social enfatiza a dimensão das políticas sociais ao longo da vida e seus benefícios, a longo prazo, para a sociedade. Através dos documentos do pacote, aprofunda-se em diferentes intervenções ao longo da vida dos cidadãos para evitar a exclusão social, dando recomenda- 
ções para a infância, a juventude, na idade laboral ou na terceira idade, com uma visão integral da inclusão social (EUROPEAN COMMISSION, 2013a; 2013b).

Entendendo que o investimento social supõe a modernização e a adaptação das políticas sociais, a Comissão propõe como alcançar essa transformação. O investimento social é visto nesta iniciativa comunitária como uma das três funções que cumprem os sistemas de bem-estar junto com a proteção social e a estabilização da economia. As políticas sociais são levadas em conta na sua dimensão, não somente imediata, mas de impacto futuro; atende-se às suas repercussões duradouras através de rendimentos econômicos e sociais que se estendem no tempo.

O enfoque do investimento social avalia na União Europeia o custo econômico do desemprego, da pobreza e da exclusão social em contraposição aos dividendos que são obtidos do investimento social (EUROPEAN COMMISSION, 2013b, p. 30-33). A pobreza e a exclusão social se unem às dificuldades de saúde, baixa alfabetização, baixa escolaridade, maior estresse nas famílias, maior criminalidade e insegurança social. A quantificação desses custos se associa a maiores gastos em saúde, em política de segurança, perdas de produtividade e de ingressos para o Estado através de impostos e aportes sociais. Assim, destaca-se a transmissão, entre gerações, desses custos a crianças de famílias desfavorecidas, perpetuando a situação de desvantagem. De acordo com isso, a Comissão coloca a importância da valoração do "custo de oportunidade" do investimento social quantificando os ganhos esperados na UE através da melhoria da inserção laboral, da melhoria da educação ou da redução da exclusão social e da pobreza.

O investimento social ajuda a "preparar" as pessoas para enfrentar os riscos da vida, mais do que simplesmente a "reparar" as consequências. Um sistema de proteção social bem elaborado deve combinar, 
segundo essa visão, uma marcada dimensão de investimento social com as funções de proteção e estabilização; assim se potencializa a eficácia das políticas sociais e se promove, de maneira continuada, uma sociedade mais inclusiva e justa. A Comunicação sobre o Investimento Social conecta a efetividade e a sustentabilidade das reformas com a justiça e obriga os Estados a prestar mais atenção a como se distribui o impacto das reformas e a combater diferentes formas de pobreza. Entre as reformas recomendadas para responder à situação demográfica da UE, insiste-se na qualidade e acessibilidade dos serviços sociais, na melhor fixação de seus objetivos, na adequação de seus benefícios e na maior simplificação administrativa (COMISIÓN EUROPEA, 2013a, p. 17-18).

A modernização das políticas sociais requer, no enfoque da Comissão, o reforço das chamadas medidas de ativação para incentivar a participação das pessoas na sociedade e na economia, e fazer isso da melhor forma de acordo com as suas capacidades. O apoio deve estar mais bem ajustado, ser temporal e condicional e estar dirigido a quem precisa dele. A individualização e integração dos serviços ou a simplificação dos procedimentos são algumas das recomendações para facilitar melhor acesso às prestações, aumentando sua eficácia (COMISIÓN EUROPEA, 2013a, p. 3-5).

Como crítica positiva ao compromisso da UE a favor do investimento social, podemos valorar a continuidade deste enfoque em outras medidas posteriores a este pacote. Entre elas, podemos citar o desenvolvimento de uma diretriz para o acesso a contas bancárias que melhore a inclusão financeira dos mais desfavorecidos, a atenção à infância com enfoque de investimento social (tal como se manifesta na Recomendação Investindo na Infância e na consequente Plataforma para o Investimento na Infância) ou a preocupação pela ação social ao longo de toda a vida do indivíduo, o envelhecimento ativo e a solidariedade entre gerações (EUROPEAN COMMISSION, 2013e; 2014a). 
O Investimento Social na União Europeia como Resposta aos Desafios Financeiros...

\subsection{A resposta aos desafios}

\section{financeiros}

A promoção do investimento social entende-se também como uma resposta necessária perante a escassez de recursos existentes, cujo melhor uso é essencial no atual marco de consolidação fiscal. Os ajustes, a condicionalidade, a individualização de serviços e a não duplicação que acabamos de mencionar também apontam para outro dos grandes temas da modernização de políticas sociais: a resposta aos problemas financeiros derivados do déficit excessivo. $\mathrm{O}$ desenvolvimento de estratégias de inclusão mais adequadas deve estar acompanhado de um uso mais eficiente dos orçamentos sociais; a modernização das políticas sociais requer que as decisões de financiamento se orientem sistematicamente, a priori, em direção aos resultados.

Tal como expressa a Comunicação:

[...] a pressão resultante que se exerce sobre os orçamentos públicos e o risco de que no futuro se produzam carências estruturais no mercado de trabalho tornam mais importante ainda a necessidade de modernizar as políticas sociais para aperfeiçoar sua eficácia e eficiência, assim como a maneira de financiá-las. Resulta essencial fazer o melhor uso possível dos recursos existentes e evitar os potenciais efeitos adversos duradouros da crise, para, assim, estabelecer as bases da produtividade e da inovação (COMISIÓN EUROPEA, 2013a, p. 3).

Esta mesma ideia é desenvolvida ao longo da Comunicação atendendo ao controle que se exerce sobre o gasto público em políticas sociais, que cobre principalmente as aposentadorias e a assistência sanitária, e faz com que na UE em torno de $29,5 \%$ do PIB seja submetido a um estrito escrutínio nos esforços de consolidação fiscal. Por isso, a Comissão chama a atenção para reformas que se concentrem 
no aumento da eficiência, com foco no seu correto planejamento para evitar repercussões negativas nos níveis de pobreza, na produtividade, no crescimento econômico, na saúde da população e na coesão social (COMISIÓN EUROPEA, 2013a, p. 5).

Perante a escassez de fundos dos Estados-membros, a Comunicação assume como seu fundamento o marco regulamentário proposto para a implantação da política de coesão no próximo período financeiro (2014-2020). O Pacote sobre Instrumentos para a Coesão Social 2014-2020 (COMISIÓN EUROPEA, 2012f) é um dos investimentos mais importantes nos objetivos sociais da Estratégia 2020, absorvendo mais de um terço do orçamento total para o período. Uma das características desta legislação é, precisamente, a concentração nos objetivos da Estratégia 2020, prevendo que o contrato de parcerias com os diferentes Estados-membros estabeleça os objetivos concretos nacionais. Por sua parte, o Fundo Social Europeu fica plenamente alinhado com os objetivos da União para educação, emprego e redução da pobreza; ao menos $20 \%$ das concessões de cada Estado-membro devem dedicar-se a investimentos que combatam a exclusão social e a pobreza.

Há que se levar em conta que este marco financeiro está definido dentro das novas regras da reforçada governança econômica. O Tratado de Estabilidade, Coordenação e Governança, com seu "Fiscal Compact", não somente consagra o controle do déficit público, requerendo sua introdução nas constituições dos Estados-membros, mas também estabelece a regra da condicionalidade: aqueles Estados que não cumpram estritamente a disciplina fiscal não terão acesso a fundos europeus. Com isso, e através deste aprofundamento na governança econômica, o sistema de transferências dos países mais ricos aos menos avançados é substituído por um acordo de mútua responsabilidade, transformando a solidariedade inter-regional (EUROPEAN CONSTITUTIONAL LAW REVIEW, 2011; GÓMEZ URQUIJO, 2012). A condicionalidade que ata o cumprimento das 
O Investimento Social na União Europeia como Resposta aos Desafios Financeiros...

exigências de déficit à recepção dos fundos é característica desta nova governança econômica e é enfatizada como garantia de sustentabilidade financeira e de adequação dos sistemas sociais. Assim, reforça-se a pretensão de uso mais eficiente e mais bem direcionado dos recursos escassos. Também se aumenta a atenção sobre o acesso e o financiamento para cumprir os objetivos sociais.

Em face dessa maior exigência para o acesso aos fundos europeus, a recente Folha de Rota apresentada pela Comissão para a implementação do Pacote de Investimento Social explicita o apoio à reforma das políticas sociais, tal como está colocada no pacote. Podemos sublinhar novamente a coerência da UE no apoio financeiro ao investimento social plasmado através da mobilização e do melhor uso dos fundos europeus. Assim, os Estados são requeridos a levar em conta o enfoque de investimento social na programação dos fundos, especialmente do Fundo Social Europeu. Isso implica também no assessoramento aos Estados-membros para desenhar suas estratégias de reforma para uma proteção social mais efetiva em termos de custo-benefício e de apoio financeiro a agentes comprometidos com a experimentação social, incluindo as empresas sociais inovadoras (EUROPEAN COMMISSION, 2014b).

Outras medidas que mostram a implicação da UE no impulso do investimento e conectadas com aspectos de financiamento são a criação do programa EaSI, que tem entre seus objetivos o apoio ao desenvolvimento de sistemas de proteção sociais adequados e o acesso ao financiamento aos empreendedores sociais; o recente uso do Fundo Europeu para os mais Necessitados (FEAD, na sigla em inglês) para proporcionar assistência em forma de alimentos, produtos de consumo básico ou medidas de inclusão social aos mais desfavorecidos e às crianças; além do desenvolvimento de novas normas para gerenciar o Fundo Europeu sobre Empreendimento Social e outras ações de apoio à difusão e motivação de empresas sociais. 


\section{O Vínculo entre as Políticas Sociais dos \\ Estados-membros e as Recomendações da Comissão na Atual Governança Econômica}

Na introdução deste artigo, mencionamos que a Comunicação sobre o Investimento Social expressa sua pretensão de estabelecer um vínculo entre as políticas sociais e as reformas recomendadas no Semestre Europeu. Após assinalar no segmento anterior os principais aportes da Comunicação, afirmamos a seguir em que medida sua concretização na política social dos Estados-membros vem favorecida ou não pelo atual marco do jogo definido pela governança econômica. Para isso, fixamo-nos no equilíbrio entre o social e o econômico no modelo de governança, à medida que o investimento social se incorpora aos instrumentos concretos de tal governança e ao papel dos Estados na sua implementação.

Em primeiro lugar, para que o investimento social possa operar neste projeto de governança econômica, este deve recolher adequadamente o equilíbrio entre o social e o econômico; a austeridade não pode afogar o desenvolvimento do enfoque de investimento social. Dado o mencionado marco de disciplina fiscal como chave da atual governança econômica, destacamos que os defensores do investimento social argumentam que não se trata de uma "opção barata" que permita poupanças orçamentais substanciais, particularmente em curto prazo. Considera-se que o trânsito em direção de uma estratégia plena de investimento social requererá recursos adicionais, e que a disciplina fiscal não deve romper esta perspectiva. Nós nos juntamos, para tanto, a quem entende que o investimento social deve estar incluído na governança macroeconômica e na regulação financeira que apoiam o crescimento sustentável (VANDENBROUCKE et al., 2011, p. 6, p. 13-14). 
O Investimento Social na União Europeia como Resposta aos Desafios Financeiros...

Assim, há que se apontar as dificuldades observadas na abordagem do investimento social europeu, como indica, por exemplo, a Confederação Europeia de Sindicatos (ETUC, 2013). Esta organização considera que a política social somente pode atingir seus objetivos se estiver plenamente inserida na governança econômica e na regulação financeira que apoia o crescimento sustentável do bem-estar na economia real. Partindo desta ideia, critica-se que o Pacote de Investimento Social não ofereça um equilíbrio adequado à governança econômica da UE. Os novos instrumentos de governança econômica, dirigidos prioritariamente em direção às finanças públicas, podem, a seu critério, impedir a estratégia de investimento social.

Enfatizam-se estas dificuldades, apesar de uma postura mais favorável à iniciativa de investimento social da UE como a defendida por algumas organizações sociais europeias, como a plataforma de ONGs europeias Social Platform (2013, p. 1). Nesta visão, o Pacote de Investimento Social é considerado uma oportunidade para reorientar as políticas atuais, para um necessário reequilíbrio entre políticas sociais e econômicas. Seria um primeiro passo em direção a uma alternativa frente ao paradigma da austeridade.

Entendemos, contudo, que, para que esta abordagem possa levar a esse equilíbrio entre o social e o econômico na atual governança econômica, é essencial um método adequado para sua translação aos Estados-membros, sendo estes responsáveis por sua política social e pelo controle do seu déficit. Para isso, consideramos fundamental que exista adequada supervisão do cumprimento das recomendações no âmbito social que assegure a sintonia da ação dos governos. Esta ideia pode se sustentar na própria Comunicação sobre o Investimento Social (COMISIÓN EUROPEA, 2013a, p. 25), segundo a qual a atual governança econômica dos Estados, mais sólida e com melhor controle orçamentário, deve estar acompanhada de melhor vigilância das políticas nos âmbitos sociais. Esperam-se, com isso, a contri- 
buição para uma melhor gestão da crise e o adequado nível de investimento social na UE.

Esta proposta se conecta com os debates já amplamente abordados sobre o aprofundamento social da união econômica e monetária. A recente Comunicação para Reforçar a Dimensão Social da União Econômica e Monetária coloca, precisamente, o reforço dessa supervisão sobre os desafios sociais e a coordenação de políticas (COMISIÓN EUROPEA, 2013b). O instrumento-chave para esta supervisão é o Semestre Europeu, implementado em 2011 como via de supervisão dos objetivos de governança econômica. Começa com a publicação, por parte da Comissão, do seu Informe Prospectivo Anual, em que são reunidas as prioridades que vão ser objeto de seguimento. Até o momento, todos os Informes Prospectivos têm incluído, entre outras medidas, dar resposta ao desemprego e às consequências sociais da crise (COMISIÓN EUROPEA, 2011b; 2012a; 2013d). Destaca-se que o Informe Prospectivo Anual para 2014 (COMISIÓN EUROPEA, 2013d) no lançamento do novo Semestre Europeu de coordenação da política econômica para o ano atual é o primeiro que conta com as indicações expressas do Pacote de Investimento Social, incluindo, entre suas prioridades: a implementação por parte dos Estados das prioridades de inclusão ativa; a preservação do acesso a benefícios de proteção social e saúde adequados; o acesso a serviços mais personalizados ("one-stop shop"); a contenção e redução da pobreza; a modernização dos sistemas de aposentadoria e a redução do impacto de gênero nas diferenças sobre os direitos de aposentadoria de homens e mulheres.

Uma vez constatada a incorporação do enfoque de investimento social às recomendações dadas aos governos neste instrumento de governança econômica, propõe-se focalizar em como se concretizará sua implementação nos Estados-membros e em qual é a margem de ação que se espera dar aos governos neste processo. 
O Investimento Social na União Europeia como Resposta aos Desafios Financeiros...

No primeiro aspecto, vemos que a implementação do programa de investimento social se concretiza nos Programas Nacionais de Reforma e nos programas de convergência que são desenvolvidos pelos Estados. A supervisão levada a cabo pela Comissão considera o avanço do cumprimento por país dos indicadores que medem os objetivos 2020, isto somado a uma avaliação específica da Comissão sobre as realizações dos Estados-membros no seguimento do Pacote de Investimento Social (EUROPEAN COMMISSION, 2014a). A avaliação realizada até o momento enquadra a resposta dos Estados dentro dos esforços que já estão fazendo para modernizar seus Estados de bem-estar e as suas estratégias contra a pobreza e a exclusão social. Nelas, detecta-se como alguns países já têm adotado um enfoque de investimento social: redirigindo seu gasto social de um modo mais eficiente, de forma a evitar a transmissão de geração em geração da pobreza com a combinação e que inclua iniciativas dirigidas a reduzir a pobreza e a apoiar a inclusão no mercado do trabalho, incrementando no último ano os recursos dedicados a políticas trabalhistas ativas, com medidas para melhorar a situação laboral dos mais desfavorecidos ou através de uma maior simplificação administrativa, tal como recomenda o enfoque de investimento social (EUROPEAN COMMISSION, 2013d). A Folha de Rota, apresentada pela Comissão para a implantação do Pacote de Investimento Social, inclui também o apoio aos Estados-membros na supervisão e avaliação dos resultados obtidos (EUROPEAN COMMISSION, 2014b).

Segundo o nosso parecer, estas evidências de mudança operadas nos Estados ainda são fracas para poder assegurar o bom resultado do Semestre Europeu como instrumento de concretização prática do investimento social nos Estados-membros. Não obstante, queremos destacar a convicção da Comissão de que é sim uma ferramenta adequada para guiar os Estados em direção ao investimento social dentro da disciplina fiscal. De fato, a Comissão aposta em maior aprofundamento do Semestre Europeu como forma de assegurar que a gover- 
nança econômica aproveite todo o seu potencial visando maior equilíbrio social e econômico (EUROPEAN COMMISSION, 2014c).

Para finalizar, é interessante destacar como este novo esquema de funcionamento implica em um câmbio importante com respeito ao Método Aberto de Coordenação, e à função dos Estados. A Comissão considera que a forma de fazer política nos Estados está sendo mudada pelo novo modelo de governança econômica, requerendo novas interações com o nível europeu e os processos nacionais para concretizar esses desenvolvimentos. Portanto, convoca-se uma mudança na função dos Estados nos seguintes aspectos. Em primeiro lugar, defende-se a participação reforçada para assegurar a compreensão pública e a aceitação das reformas, com maior envolvimento dos parlamentos nacionais, dos agentes sociais e da sociedade civil. Por outro lado, propõe-se um movimento partindo da consideração das recomendações específicas por país para a definição de políticas e reformas que sejam necessárias à zona do euro como conjunto. Finalmente, defende-se uma melhor implementação das recomendações específicas por parte dos Estados-membros considerando o interesse comum. Em definitivo, convocam-se os governos a um maior envolvimento para que finalmente tomem decisões de política que obedeçam aos interesses mais amplos da UE (EUROPEAN COMMISSION, 2014c).

\section{Conclusões}

O reforço da governança econômica centrado no controle do déficit é compatível com o próprio modelo desenhado para a União Econômica Monetária e com os problemas de financiamento suscitados pela crise da dívida. Contudo, seus efeitos no desenvolvimento das políticas nacionais e no gasto dos Estados-membros acentuam as divergências e ameaçam o não cumprimento do modelo de economia social de mercado. Consideramos que o cumprimento dos objetivos sociais da Estratégia 2020 - assim como dos próprios fins estabeleci- 
O Investimento Social na União Europeia como Resposta aos Desafios Financeiros...

dos nos Tratados para o bem-estar dos cidadãos - requer um maior reforço da dimensão social da União Econômica e Monetária e do mercado interno.

Nessa linha, enquadra-se a iniciativa lançada pela Comissão Europeia para promover o investimento social, na nossa opinião uma valiosa mostra de seu interesse por contrapor a ineficiência dos sistemas de proteção perante a crise e dar resposta às demandas sociais que esta propõe. Assim, assume as críticas realizadas aos países da UE pela sua falta de investimento social e incorpora as propostas teóricas que associam o investimento social a melhores resultados de bem-estar social. É interessante destacar que não se trata de uma iniciativa isolada, mas, no marco do modelo de economia social de mercado, soma-se a outras lançadas durante a crise para paliar a pobreza ou a exclusão ou promover um âmbito de negócios socialmente mais responsável.

A Comunicação sobre o Investimento Social tem, entre outras, a virtude de dar um passo a mais em direção a algo amplamente demandado: a equiparação dos objetivos sociais e econômicos em uma nova estrutura de governança econômico-financeira. Supõe, em nossa opinião, um importante reforço da linha recentemente empreendida para desenvolver mais a reduzida dimensão social da União Econômica e Monetária. Destacamos especialmente o impulso à supervisão das metas sociais dentro do Semestre Europeu como instrumento de controle que as equipara nesse nível com as macroeconômicas.

Contudo, o enquadramento na estrutura de governança dos objetivos sociais estende a estes também a condicionalidade. Esta condicionava o recebimento de fundos por parte dos Estados ao cumprimento dos objetivos econômicos fixados. Na Comunicação sobre o Investimento Social, adiciona-se ainda mais uma condicionalidade que podemos chamar de segundo nível de proposta para o recebimento de ajudas sociais pelos cidadãos $-\mathrm{o}$ apoio deve ser mais bem ajustado, temporal $\mathrm{e}$ 
condicionalmente, e dirigir-se a quem dele necessita. Tudo isso se dá, em ambos os níveis, em beneficio da melhor gestão dos recursos escassos de uns Estados desbordados pelos déficits excessivos.

A abordagem genuína de investimento social não coincide com uma versão mais barata da política social, mas que, provavelmente, demanda mais recursos e que estes sejam mais bem gerenciados. Logo, o desenho europeu, valioso enquanto sua perspectiva no longo prazo e a implicação das pessoas ao longo de toda a vida, corre o risco de ser uma resposta fácil às dificuldades da disciplina fiscal. Assumimos que ainda é longo o caminho para lograr o equilíbrio econômico-social na nova governança da UE, mas entendemos que ele contribui com a iniciativa a favor do investimento social. Neste complexo marco em que os aspectos macroeconômicos e fiscais vêm sendo destacados, vemos signos positivos sobre a viabilidade do enfoque de investimento social e sobre a coerência da Comissão com ele. Entre outras, as iniciativas desdobradas com posterioridade ao Pacote de Investimento Social em seguimento de suas linhas mestras, bem como as dedicadas à sua supervisão e desenvolvimento, e a sua conexão com os fundos europeus. Portanto, é essencial que as recomendações concretas dadas aos Estados-membros dentro do Semestre Europeu se adaptem a uma abordagem genuína de investimento social e não a um mero remendo para solucionar os problemas orçamentários. A forma como se acaba de incorporar o enfoque de investimento social às prioridades fixadas no Semestre Europeu marca um ponto decisivo em seu desenvolvimento e na própria governança econômica.

Constatada também a incorporação deste enfoque de investimento social à supervisão dos Estados (e o tímido desenvolvimento que se tem dado a eles), resta dizer que se observa também interessante via de mudança no papel que os governos possam tomar no seguimento das recomendações no âmbito social. Na primeira etapa da crise, temos assistido à persistência não só, obviamente, da diversidade dos modelos de Estados de bem-estar, mas também da consolidação fis- 
O Investimento Social na União Europeia como Resposta aos Desafios Financeiros...

cal diferenciada e de seu diverso impacto na política social. Agora observamos a Comissão pedindo um novo papel dos Estados para que suas políticas de seguimento das recomendações europeias estejam em consonância com o bem comum.

\section{Nota}

1. Communication from the Commission: Towards Social Investment for Growth and Cohesion - Including Implementing the European Social Fund 2014-2020 (2013); Commission Recommendation: Investing in Children Breaking the Cycle of Disadvantage (2013); Staff Working Document: Evidence on Demographic and Social Trends - Social Policies' Contribution to Inclusion, Employment and the Economy (Part 1) (2013); Staff Working Document: Evidence on Demographic and Social Trends - Social Policies' Contribution to Inclusion, Employment and the Economy (Part 2) (2013); Staff Working Document: Follow-up on the Implementation by the Member States of the $2008 \mathrm{Eu}-$ ropean Commission Recommendation on Active Inclusion of People Excluded from the Labour Market - Towards a Social Investment Approach (2013); Staff Working Document: 3rd Biennial Report on Social Services of General Interest (2013); Staff Working Document: Long-term Care in Ageing Societies - Challenges and Policy Options (2013); Staff Working Document: Confronting Homelessness in the European Union (2013); Staff Working Document: Investing in Health (2013); Staff Working Document: Social Investment through the European Social Fund (2013); Citizens' Summary - Social Investment Package for Growth and Cohesion (2013); Social Investment Package: Key Facts and Figures (2013).

\section{Referências Bibliográficas}

AVRAM S. et al. The Distributional Effects of Fiscal Consolidation in Nine EU Countries. Euromod Working Paper, n. EM 2/13, 2013. Disponível em: 
Laura Gómez Urquijo

$<$ http://www.iser.essex.ac.uk/publications/working-papers/euromod/em213.pdf>. Acesso em: 18 out. 2013.

CANTILLON, B. The Paradox of the Social Investment State: Growth, Employment and Poverty in the Lisbon Era. Journal of European Social Policy, v. 21, n. 5, p. 432-449, nov. 2011.

CHANDLER D. Beyond Neoliberalism: Resilience, the New Art of Governing Complexity. Resilience: International Policies, Practices and Discourses, v. 2, n. 1, p. 47-63, 2014.

COMISIÓN EUROPEA. Comunicación de la Comisión, de 3 de marzo de 2010, denominada "Europa 2020: Una estrategia para un crecimiento inteligente, sostenible e integrador". COM (2010) 2020, 3 mar. 2010. Bruxelas: Comisión Europea, 2010a.

Comunicación de la Comisión al Parlamento Europeo, al Consejo, al Comité Económico y Social Europeo y al Comité de las Regiones. La plataforma europea contra la pobreza y la exclusión social: un marco europeo para la cohesión social y territorial. COM (2010) 758 Final, 16 dez. 2010. Bruxelas: Comisión Europea, 2010b.

Propuesta de Reglamento del Parlamento Europeo y del Consejo relativo a un Programa de la Unión Europea para el Cambio y la Innovación Sociales. COM (2011) 609 Final, 6 out. 2011. Bruxelas: Comisión Europea, 2011a.

Comunicación de la Comisión Estudio Prospectivo Anual sobre el Crecimiento 2012. COM (2011) 0815 Final, 23 nov. 2011. Bruxelas: Comisión Europea, 2011b.

Comunicación de la Comisión Estudio Prospectivo Anual sobre el Crecimiento 2013. COM (2012) 750 Final, 28 nov. 2012. Bruxelas: Comisión Europea, 2012a.

Comunicación de la Comisión, “Hacia una recuperación generadora de empleo". COM (2012) 173, 18 abr. 2012. Bruxelas: Comisión Europea, 2012b.

Comunicación de la Comisión “Promover el empleo juvenil”. COM (2012) 727, 5 dez. 2012. Bruxelas: Comisión Europea, 2012c. 
O Investimento Social na União Europeia como Resposta aos Desafios Financeiros...

Libro Blanco "Agenda para unas pensiones adecuadas, seguras y sostenibles”. COM (2012) 55, 16 fev. 2012. Bruxelas: Comisión Europea, 2012d.

Comunicación de la Comisión "Una industria europea más fuerte para el crecimiento y la recuperación económica”. COM (2012) 582, 10 out. 2012. Bruxelas: Comisión Europea, 2012e.

Política de Cohesión (2014-2020). Bruxelas: Comisión Europea, 2012f.

Comunicación de la Comisión al Parlamento Europeo, al Consejo, al Comité Económico y Social Europeo y al Comité de las Regiones Hacia la inversión social para el crecimiento y la cohesión, incluida la ejecución del Fondo Social Europeo 2014-2020. COM (2013) 83 Final, 20 fev. 2013. Bruxelas: Comisión Europea, 2013a.

Comunicación de la Comisión al Parlamento Europeo, al Consejo, al Comité Económico y Social Europeo y al Comité de las Regiones. Semestre Europeo 2013: Recomendaciones específicas por país sacar a Europa de la crisis. COM(2013) 350 final, 29 mai. 2013. Bruxelas: Comisión Europea, 2013 b.

Comunicación Reforzar la dimensión social de la Unión Económica y Monetaria. COM (2013) 690 Final, 2 out. 2013. Bruxelas: Comisión Europea, 2013c.

Comunicación de la Comisión. Semestre Europeo 2013: Recomendaciones específicas por país sacar a Europa de la crisis. COM (2013) 350 final, 29 mai. 2013. Bruxelas: Comisión Europea, 2013d.

CONSEJO EUROPEO. Realización del Semestre Europeo. Informe 22 de febrero de 2012 (27.02) (OR. en) 6662/12. Bruxelas: Consejo Europeo, 2012.

ETUC - European Trade Union Confederation. The Social Investment Package. ETUC Position Adopted at the Extraordinary Executive Meeting of 23 april 2013. Disponível em: <http://www.etuc.org/a/11314>; <http://www. etuc.org/IMG/pdf/SIP_EN_Final_Resolution.pdf>. Acesso em: 18 out. 2013.

EUROPEAN COMMISSION. Communication from the Commission: Reinforcing Economic Policy Coordination. COM (2010) 250 final. Bruxelas: European Commission, 2010.

Employment and Social Development in Europe 2011. Bruxelas: European Commission, 2012. 
Commission Staff Working Document Follow-up on the Implementation by the Member States of the 2008 European Commission Recommendation on Active Inclusion of People Excluded from the Labour Market - Towards a Social Investment Approach. SWD (2013) 39 final. Bruxelas: European Commission, 2013a.

Commission Staff Working Document Evidence on Demographic and Social Trends. Social Policies' Contribution to Inclusion, Employment and the Economy I/II. SWD (2013) 38 final. Bruxelas: European Commission, 2013b.

Draft Joint Employment Report Accompanying the Communication from the Commission on Annual Growth Survey 2014. COM (2013) 801 final. Bruxelas: European Commission, 2013c.

Employment, Social Affairs \& Inclusion, Social Investment Package - Key Facts and Figures. Bruxelas: European Commission, 2013d.

Commission Recommendation of 20.2.2013 Investing in Children: Breaking the Cycle of Disadvantage. C (2013) 778 final. Bruxelas: European Commission, 2013e.

Social Investment Package: Taking Stock of Achievements One Year on. Bruxelas: European Commission, 2014a. Disponível em: <http://ec.europa.eu/social/main.jsp?langId=es \&catId=89\&news $I d=2037 \&$ furtherNews=yes $>$. Acesso em: 11 mar. 2014.

Policy Roadmap for the Implementation of the Social Investment Package. 2014b. Disponível em: <http://ec.europa.eu/social/BlobServlet?docId=11150\&langId=en $>$. Acesso em: 11 mar. 2014.

Communication 2014 European Semester: Country-Specific Recommendations Building Growth. Bruxelas: European Commission, 2014c.

EUROPEAN CONSTITUTIONAL LAW REVIEW. Rethinking Solidarity in the EU, from Fact to Social Contract. European Constitutional Law Review, v. 7, n. 2, p. 169-172, 2011.

EUROSTAT. Government Expenditure by Sub-Sector of General Government. 2012. Disponível em: <http://epp.eurostat.ec.europa.eu/statistics_explained/index.php/Government_expenditure_by_sub-sector_of_general_government>. Acesso em: 11 mar. 2014. 


\section{O Investimento Social na União Europeia como Resposta aos Desafios Financeiros...}

Europe 2020 Headline Indicators. 2013. Disponível em: <http://epp. eurostat.ec.europa.eu/portal/page/portal/europe_2020_indicators/headline_ indicators $>$. Acesso em: 11 mar. 2014.

FERREIRO, J. et al. Similarities and Differences in the Composition of the Public Expenditures in the European Union. Journal of Economic Issues, v. 46, n. 3, p. 633-659, 2012.

GÓMEZ URQUIJO, L. El Tratado de Estabilidad, Coordinación y Gobernanza, dentro del nuevo marco condicional de cohesión social de la Unión Europea. Revista de Derecho Comunitario Europeo, n. 42, p. 521-541, 2012.

HEIDENREICH, M.; BISCHOFF, G. The Open Method of Co-Ordination: A Way to the Europeanization of Social and Employment Policies? Journal of Common Market Studies, v. 46, n. 3, p. 497-532, 2008.

HEMERIJCK, A.; DRÄBING, V.; VIS, B.; NELSON, M.; SOENTKEN, M. European Welfare States in Motion. Newjobs Working Paper, n. D5.2, mar. 2013. Amsterdã: Lund University, 2013. Disponível em: <http://www.neujobs.eu/sites/default/files/NEUJOBS_WP_D5\%202_revision_ FINAL_0.pdf>. Acesso em: 11 mar. 2014.

JENSON, J. Redressing Citizenship Regimes after Neoliberalism: Moving Towards Social Investment. In: MOREL, N.; PALIER, B.; PALME, J. (Org.). Towards a Social Investment Welfare State? Bristol: Policy Press, 2011.

NIKOLAS, R. Towards Social Investment? Patterns of Public Policy in the OECD World. In: MUREL, N.; PALIER, B.; PALMER, B. What Future for Social Investment? Estocolmo: Institute for Future Studies, 2009. Disponível em: <http://www.iffs.se/eng/publikation/what-future-for-social-investment>. Acesso em: 11 mar. 2014.

REID, J. The Neoliberal Subject Resilience and the Art of Living Dangerously. Revista Pléyade, n. 10, p. 143-165, 2012.

SOCIAL PLATFORM. Social Platform's Position on the Social Investment Package April 26, 2013. Disponível em: <http://www.socialplatform.org/documents/position-paper-on-the-social-investment-package/>; <http:// www.socialplatform.org/wp-content/uploads/2013/06/20130426_SocialPlatform_positionpaper_SIP_final.pdf>. Acesso em: 18 mar. 2014. 
Laura Gómez Urquijo

UN SISTEMA de economía social de mercado para una Europa solidaria, responsable y productiva. Revista de Fomento Social, n. 265, fascículo 67, p. 5-29, 2012.

VANDENBROUCKE, F.; DIRIS, R.; VERBIST, G. Excessive Social Imbalances and the Performance of Welfare States in the EU. 2013. Disponível em: <https://www.kuleuven.be/euroforum/viewpic.php?LAN=E\& TABLE=DOCS\&ID=855>. Acesso em: 18 mar. 2014.

VANDENBROUCKE, F.; HEMEIJCK, A.; PALIER, B. The EU Needs a Social Investment. Pact Opinion Paper, n. 5, mai. 2011. Bruxelas: Observatoire Social Europeén.

VAN KERSBERGEN, K.; HEMERIJCK, A. Two Decades of Change in Europe: The Emergence of the Social Investment State. Journal of Social Policy, v. 41, n. 3, p. 475-492, 2012.

ZEBROWSKI, C. Governing the Network Society: A Biopolitical Critique of Resilience. Political Perspectives, v. 3, n. 1, 2009.

\section{Resumo}

\section{O Investimento Social na União Europeia como Resposta aos Desafios Financeiros e Sociais da Crise}

Este artigo mostra como se aborda o investimento social por parte da União Europeia no peculiar e atual contexto de recortes de gastos sociais e reforço da governança econômica. Para isso, focaliza o estudo da atuação da UE, especialmente da Comissão, e as iniciativas implantadas desde o início da crise.

Esta análise parte das propostas europeias para atingir os objetivos 2020, destacando a dupla intervenção da UE e dos Estados. Considerando tais iniciativas, vê-se o aporte do recentemente lançado Pacote de Investimento Social sobre a modernização das políticas sociais, respondendo aos desafios demográficos e financeiros da UE. Por último, questiona-se em que medida se produz efetivamente o vínculo entre as recomendações da Comissão 
O Investimento Social na União Europeia como Resposta aos Desafios Financeiros...

a favor do investimento social e as políticas dos Estados-membros dentro das particulares regras do jogo da nova governança econômica.

Palavras-chave: Investimento Social - Crise - Coesão - União Europeia

\section{Abstract}

\section{The Social Investment in the European Union as an Answer to the Financial and Social Challenges in the Crisis}

This article deals with the idea of social investment given by the European Union in the peculiar current context of cuts of social expenses and reinforcement of the economic governance. With this aim, the work focuses specially in the initiatives provided by the EU, mainly by the Comission from the breakout of the crisis.

Thus, this analysis takes firstly into account those European proposals aimed to achieve 2020 objectives, emphasazing the double intervention EU Member States. Considering these initiatives we deal with the contribution of the recently launched Package for the social investment on the reform of the social policies, answering to the demographic and financial challenges of the EU. Finally, we question to which extent there is an effective link between the Commission's recommendations promoting social investment and the Member States policies in the new economic governance framework.

Keywords: Social Investment - Crisis - Cohesion - European Union 